\title{
CULTURA DOS DIALETOS E EXPERIÊNCIA ESTÉTICA: A SOCIEDADE DOS MASS MEDIA, EM GIANNI VATTIMO
}

\section{CULTURE OF DIALETTS AND AESTHETIC EXPERIENCE: THE SOCIETY OF MASS MEDIA, IN GIANNI VATTIMO}

\author{
Adelino Pereira da Silva ${ }^{1}$ \\ Edmilson Alves de Azevêdo
}

Recebido em: 06/2018

Aprovado em: 10/2018

\begin{abstract}
Resumo: O presente estudo trata-se de uma discussão com vistas à investigação em torno da maneira como Gianni Vattimo tece uma reflexão filosófica sobre a "pós-modernidade". Mediante o pensamento deste filósofo italiano, aponta-se, a partir de suas argumentações em torno do pósmoderno, para a necessidade de se refletir acerca das condições atuais em relação à cultura e da nova forma de compreensão de mundo para a sociedade contemporânea, pois que, conforme Vattimo, se deve pensá-la, em seu conjunto, como algo que não se limita a leituras parciais de seu contexto. Para tanto, recorre-se às interpretações de Vattimo em torno do pensamento de filósofos, tais quais Friedrich Nietzsche e Martin Heidegger, nos quais encontramos bases necessárias para uma crucial compreensão do nosso tempo e, consequentemente, o desdobramento de seus pensamentos filosóficos sobre a temática. Assim, propõe-se uma reflexão sobre as novas experiências advindas com a pós-modernidade, notadamente sobre a atuação dos mass media nessa sociedade, procurando elucidar a nova configuração cultural presente na assim chamada sociedade pós-moderna e, consequentemente, a atuação dos mass media nessa sociedade globalizada, principalmente mediante a leitura da obra A Sociedade Transparente, visando sua proposta de emancipação do pensamento, tendo em vista ser possível apresentar a cultura dos dialetos e a experiência artística presente neste contexto cultural, como sendo característico do que se chamará de uma sociedade dos media.
\end{abstract}

Palavras-chave: Pós-modernidade. Mass Media. Cultura dos Dialetos. Experiência Estética.

\begin{abstract}
The present study deals with a discussion about the investigation of Gianni Vattimo's philosophical reflection on "post-modernity". Through the thinking of this Italian philosopher, it is pointed out, from his arguments about the postmodern, to the need to reflect on the current conditions in relation to culture and the new way of understanding the world for contemporary society, because, according to Vattimo, one should think of it as a whole, as something that is not limited to partial readings of its context. To this end, we use Vattimo's interpretations of the philosophers' thinking, such as Friedrich Nietzsche and Martin Heidegger, in which we find the necessary bases for a crucial understanding of our time and, consequently, the unfolding of his philosophical thoughts on the subject. Thus, it is proposed a reflection on the new experiences coming from postmodernity, notably on the performance of the mass media in this society, seeking to elucidate the new cultural configuration present in the so-called postmodern society and, consequently, the mass action media in this globalized society, mainly through the reading of The Transparent Society, aiming at its proposal of emancipation of thought, in view of being possible to present the culture of the dialects and the artistic experience present in this cultural context, as being characteristic of what will be called a media society.
\end{abstract}

\footnotetext{
${ }^{1}$ Doutorando em Filosofia pela UFPB. E-mail: ade.lino@yahoo.com.br
} 
Keywords: Postmodernity. Mass Media. Dialect Culture. Aesthetic Experience.

\section{Introdução}

A discussão em torno da pós-modernidade, usualmente, parece se legitimar a partir dos impactos socioeconômicos e, sobretudo, dos culturais. A pós-modernidade, assim, conforme a proposta erguida por Gianni Vattimo, é pensada, em seu conjunto, como algo que não se limita a leituras parciais de seu contexto, mas que se estende aos dias atuais. Assim, o tema a ser trabalhado nessa pesquisa é o modo como o filósofo italiano vai pensar a pósmodernidade a partir dos mass media.

São objetivos do trabalho se ocupar de uma discussão em torno do aspecto mais filosófico sobre essa temática, abarcando as condições histórico-culturais da experiência do presente, as quais permitem a Vattimo discutir a pós-modernidade sem afastar-se da filosofia (ou cair em filosofismos ${ }^{2}$ ). Fazer uma reflexão sobre a nova experiência proposta pela pósmodernidade levando em consideração os mass media. Assim, buscar-se-á elucidar a nova configuração cultural presente na assim chamada sociedade pós-moderna e, consequentemente, a atuação dos mass media nessa sociedade globalizada. Temos como horizonte, a leitura de A Sociedade Transparente, para o salto (ou início) rumo a uma sociedade pós-moderna (ou da pós-modernidade) visando sua proposta de emancipação do pensamento (cultura dos dialetos) e a experiência artística presente na vida cotidiana deste contexto cultural.

A fim de contemplar o tema, encaminhamos a pesquisa a partir das reflexões de Gianni Vattimo, quando ele se propõe a, em seu livro $O$ fim da modernidade: niilismo $e$ hermenêutica na cultura pós-moderna, esclarecer a "[...] relação que liga as conclusões da reflexão de Nietzsche e de Heidegger, a que constantemente se faz referência, com os discursos, mais recentes, sobre o fim da época moderna e a pós-modernidade" (VATTIMO, 1996, p. 5). Ele recorre a esses filósofos relacionando-os às problemáticas levantadas por eles - inicialmente, a discussão em Nietzsche do "eterno retorno" e, depois, a de Heidegger em torno do ultrapassamento da metafísica - com o fito de apontar "que as esparsas e nem sempre coerentes teorizações do pós-moderno adquirem rigor e dignidade filosófica" (VATTIMO, 1996, p. 5). Feito essa discussão, que constitui o aspecto filosófico da

\footnotetext{
${ }^{2}$ Filosofismo, aqui, pode ser entendido como uma falsa filosofia ou, então, um abuso da filosofia, na medida em que extrapola limites da própria filosofia ou do filosófico.
} 
modernidade, interessa refletir ou problematizar os mass media como aquilo que, segundo Vattimo, determina o pós-moderno. Para tanto, discutiremos a cultura dos dialetos e experiência estética na sociedade dos mass media a partir da obra A Sociedade Transaparente, do referido filósofo.

Apresentamos, deste modo, como hipóteses, a partir das indicações críticas feitas pelos filósofos Nietzsche e Heidegger na Modernidade, quando Vattimo apresenta a pósmodernidade como uma radicalização da tradição filosófica moderna, que: a filosofia pósmoderna leva alguns aspectos em consideração, como as implicações resultantes do niilismo (termo trabalhado a partir de Heidegger e Nietzsche), da modernidade, da crise da Metafísica e da acepção global da história, além da presença e experiência dos mass media, do desenraizamento e, notadamente, da perda de força das estruturas estáveis, implicando na compreensão enfraquecida do ser. Também partimos do entendimento de que a orientação da pós-modernidade filosófica, proposta por ele, se expressa a partir da categoria da Verwindung, consentindo em uma reconfiguração do próprio papel da filosofia na época em que a Metafísica chega ao fim. Finalmente, parte-se da visada de que a sociedade pós-moderna adquire um novo sentido, o tecnológico, e que a atuação dos mass media provocou o desenraizamento das condições utópicas do moderno, proporcionando a emancipação do pensamento, na medida em que abriu caminhos à cultura dos dialetos e a novas experiências, inclusive estéticas, (re)configurando o pensamento filosófico ocidental.

\section{Moderno, pós-moderno}

Segundo Perry Anderson (1999, p. 9) a ideia de "pós-modernismo" surgiu no mundo hispânico no ano de 1930. Nesse período, o termo se restringia ao âmbito estético, sem fazer alusões à política ou à filosofia, e situava-se longe dos grandes centros intelectuais como a Inglaterra e os Estados Unidos. Reaparecendo nos anos 1950, mais precisamente em Nova York e Chicago, depois de percorrer as periferias do mundo, o pós-moderno foi designado como algo a menos do que moderno. Configurando-se como uma denúncia aos ideais do liberalismo e do socialismo, em vistas à separação entre razão e liberdade, o termo pretendia apresentar uma "ficção contemporânea incapaz de sustentar a tensão modernista com uma sociedade circundante cujas divisões de classe tornavam-se cada vez mais amorfas com a prosperidade do pós-guerra" (ANDERSON, 1999, p. 19). Na década de 1960, 
ela mudou de novo - ainda amplamente - para sinal fortuito, estranho. Em meados da década o crítico Leslie Fied [...] celebrou o surgimento de uma nova sensibilidade entre a geração mais jovem da América, que era uma geração dos "excluídos da história", mutantes culturais cujos valores desinteresse e desligamento, alucinógenos e direitos civis - encontravam expressão e acolhida numa nova literatura pós-moderna. (ANDERSON, 1999, p. 19).

A cristalização do termo pós-moderno só aconteceu nos anos 1970, no momento em que apareceu pela primeira vez impresso em "uma publicação que trazia expressamente o título e subtítulo Revista de Literatura e Cultura Pós-modernas" (ANDERSON, 1999, p, 23). Graças a esta acolhida, pode-se, pela primeira vez, "estabelecer a ideia de pós-moderno como referência coletiva" (ANDERSON, 1999, p, 23). Para além da problemática sobre se o pósmodernismo seria apenas uma tendência artística ou (também um) fenômeno social, "nem olímpico e distante como nem boêmio e rebelde como aquelas, o pós-modernismo surge como um tipo diferente de acomodação entre a arte e a sociedade" (ANDERSON, 1999, p. 26).

Nesse contexto, encontramos o primeiro filósofo, Jean-François Lyotard, com a obra $A$ Condição Pós-moderna, de 1979, a tratar sobre essa temática. Segundo Anderson (1999, p. $32)$,

a oportunidade imediata para $A$ condição pós-moderna, no entanto, foi uma encomenda para produzir um relatório sobre o estado do "conhecimento contemporâneo" para o conselho universitário do governo do Quebec, onde o partido nacionalista de René Levesque tinha acabado de assumir o poder.

Nesse texto, Lyotard (2008, p. XV) "tem por objeto a posição do saber nas sociedades mais desenvolvidas". Assim, o autor associa a pós-modernidade às sociedades mais desenvolvidas, à sociedade pós-industrial, "na qual o conhecimento tornara-se a principal força econômica de produção numa corrente desviada dos Estados nacionais, embora ao mesmo tempo tendo perdido suas legitimações tradicionais" (ANDERSON, 1999, p. 32).

Se a sociedade era agora melhor imaginada, "não como um todo orgânico nem como um campo de conflito dualista (Parsons ou Marx) mas como uma rede de comunicação linguística, a própria linguagem - 'todo o vínculo social'”(LYOTARD, 2008. p. 32) concebia-se de uma pluralidade de jogos diferentes, "cujas regras não se podem medir, e inter-relação agonísticas" (LYOTARD, 2008. p. 32). Nesses feitios, a ciência se tornou um jogo de linguagem dentre outros: "já não podia reivindicar o privilégio imperial sobre outras formas de conhecimento, que pretendera nos tempos modernos" (LYOTARD, 2008. p. 32). A 
sua verdadeira pretensão à superioridade como "verdade denotativa" em relação aos "estilos narrativos do conhecimento comum" ocultava a base de sua própria legitimação, que classicamente consistiu em duas formas grandiosas de narrativas ${ }^{3}$.

A condição pós-moderna abancaria no colapso desses relatos que, em conflito com a ciência, serão reduzidos a fábulas (Cf. LYOTARD, 2008). O pós-moderno implica deste modo na "incredulidade em relação aos grandes relatos" (LYOTARD, 2008, p. XVIII), dirigindo agora sua atenção ao desuso do dispositivo metanarrativo que excita os indivíduos a viver numa "pragmática das partículas de linguagem”, de “jogos de linguagem diferentes”, na "heterogeneidade dos elementos", num "determinismo local” (LYOTARD, 2008, p. XVIII).

A partir a reflexão de Lyotard sobre o saber na contemporaneidade, pode-se dizer que o pós-moderno indica o saber como principal instrumento de poder dessa sociedade, e que embora esteja trasladado em informação, possui ainda uma sensibilidade "aguçada para as diferenças" e a "capacidade de suportar o incomensurável" (LYOTARD, 2008, p. XVIII). Deste modo, a acepção de pós-moderno, tal como apresentada por Lyotard, ampara-se na "queda da credulidade das metanarrativas" e numa sensibilidade para as diferenças.

Tendo em vista esta estrutura conceitual, importa direcionar a presente reflexão às contribuições de Gianni Vattimo sobre o pós-moderno e a maneira como ela se insere no debate e na proposta do presente trabalho.

Conforme o autor, o pós-moderno será mais bem teorizado e discutido, com rigor filosófico, a partir de Nietzsche e Heidegger, uma vez que eles já haviam evidenciado as novas condições da existência no mundo industrial tardio, o que, por assim dizer, os caracterizam de maneira definitiva como irredutíveis à pura e simples Kulturkritik (crítica da cultura ou crítica cultural), que percorre toda a filosofia e a cultura do início do século XX. E,

considerar a crítica heideggeriana ou o anúncio nietzschiano do niilismo consumado como momentos "positivos" para uma reconstrução filosófica, e não apenas como sintomas e denúncias da decadência [...] só é possível desde que se tenha a coragem [...] de ouvir com atenção os discursos das artes, da crítica literária, da sociologia, sobre a pós-modernidade e suas peculiaridades. (VATTIMO, 1996, p. 5-6).

Com base na herança nietzschiano-heideggeriana, Vattimo reconhece a "experiência" do niilismo como uma alternativa válida para a sua interpretação da existência na pós-

\footnotetext{
${ }^{3}$ Segundo Lyotard (2008, p. 32), “a primeira, derivada da Revolução Francesa, colocava a humanidade como agente heroico de sua própria libertação através do avanço do conhecimento; a segunda, descendente do idealismo alemão, via o espírito como progressiva revolução da verdade. Esses foram os grandes mitos justificadores da modernidade".
} 
modernidade. Tal herança ele não recebe passivamente, pois reelabora as noções fundamentais de seus grandes mestres. Nesta esteira, podemos apontar os aspectos da conceituação filosófica vattimiana de pós-modernidade e, a partir daí, o aparecimento da cultura dos dialetos e as novas experiências com os meios de comunicação de massa.

\section{Legado de Nietzsche e Heidegger para a pós-modernidade}

Nesse momento, iremos apresentar o legado de Nietzsche e Heidegger para a pósmodernidade com referência a lógica discursiva trazida por Vattimo, apresentando o esclarecimento que liga as conclusões desses dois filósofos, a que estamos constantemente fazendo referência com os discursos mais atuais sobre o fim da época moderna e a pósmodernidade.

De início, um tema reentrante e de importância para nossa discussão a partir da reflexão de Nietzsche, que abarca o que ele chama por "morte de Deus", é a "crise do sujeito" e consequentemente a "crise da subjetividade". Citando Vattimo, Teixeira (2005, p. 33) diz que

a "crise da subjetividade" não toca somente à noção de sujeito. Em Nietzsche, por exemplo, a crise da subjetividade anuncia o desmascaramento da superficialidade da consciência. Tal crise tem a ver com a distinção entre apolíneo e dionisíaco feita por Nietzsche em sua obra O Nascimento da Tragédia. Nessa obra, o autor condena o "socratismo". Só que a crítica feita não é contra a "autoconsciência" de Sócrates. "Sócrates, que é o campeão de apolíneo - da forma definida, da racionalidade separada e desenraizada da relação constitutiva com o dionisíaco - o mundo da vida imediata, das pulsões - é também o campeão da autoconsciência, já que assim se pode definir também o seu saber de não saber. Mas, exatamente na medida na qual se absolutiza e se distancia das suas raízes dionisíacas - míticas, irracionais, vitais - a racionalidade apolínea perde qualquer e toda a vitalidade, se torna decadência.

Tal feitio não se trata simplesmente em "desmentir" a sua verdade, porém em considerá-la não vital. Deste modo, Nietzsche procurou desmascarar as formas definidas de valor e da própria noção de verdade. A arguição nietzscheriano não para aqui, pois não se trata de ficar numa posição de puro "desmascaramento da superficialidade" da consciência do sujeito, ele progride na direção do niilismo e da desconstrução da noção de verdade e de ser (Cf. TEIXEIRA, 2005). Segundo Vattimo (Cf. 1996), pode-se dizer que a crise da subjetividade referida por esse filósofo é o anúncio da "morte de Deus", que será 
reformulada pela primeira vez na obra nietzscheriano Gaia Ciência.

Adiante, a partir da Verwindung, conduta pós-metafísica da hermenêutica vattimiana, categoria brandida em sua primeira obra As Aventuras da Diferença (VATTIMO, 1988) e, posteriormente, melhor desenvolvida em Pensiero Debole (VATTIMO, 1983), Vattimo faz o prelúdio de um redimensionamento do pensamento filosófico que estaria nela identificado, o que, outrora, já estava radicado no pensamento de Nietzsche e também no Heidegger, como a prática filosófica da contemporaneidade. Dado esse ponto de partida, ele empreende uma sofisticação mediante o pensiero debole, que, adotando a Verwindung como atitude pósmetafísica, procura entender as prováveis implicações que se referem à tese do enfraquecimento das composições metafísico-modernas para o contexto das teorizações filosóficas sobre o pós-moderno.

Nos termos do filósofo italiano:

Verwindung é a palavra que Heidegger usa, de resto bastante raramente (uma página de Holzwege, um ensaio de Vorträge und Aufsätze e, sobretudo, o primeiro dos dois ensaios de Identität und Differenz), para indicar algo análogo à Ueberwindung, a superação ou ultrapassamento, mas que se distingue desta por nada possuir da Aufhebung dialética, nem do "deixar para trás" que caracteriza a relação com um passado que não tem mais nada a dizer-nos. (VATTIMO, 1996, p. 169).

A pós-modernidade filosófica, segundo Vattimo (1996, p. 170) pode-se sustentar legitimamente que nasce na obra de Nietzsche,

para sermos mais precisos, no espaço que separa a segunda consideração inatual (Sobre a utilidade e o dano dos estudos históricos para a vida, 1874) do grupo de obras que, a poucos anos de distancia, se inicia com Humano, demasiado humano (1878) e que também compreende Aurora (1881) e A gaia ciência ${ }^{4}$ (1882).

Portanto, as teorizações realizadas por Nietzsche, e também por Heidegger, não devem ser vistas tão somente como uma simples crítica cultural que marcou o século $\mathrm{XX}$, uma vez que as condições coevas de existência tornam cada vez mais aceitáveis as teses aludidas por esses precursores de uma filosofia pós-moderna. Nesta esteira, no pensamento vattimiano também se identifica:

\footnotetext{
${ }^{4}$ Entende-se que "[...] a Gaia Ciência, em que Nietzsche fala pela primeira vez da morte de Deus, é a idéia do eterno retorno do igual; que significa, entre outras coisas, o fim da época da superação, isto é, do ser pensado sob o signo do novum" (VATTIMO, 1996, p. 173-174).
} 
uma radical mudança de paradigma no modo de conceber a realidade. Uma mudança na qual tenderia a reconhecer o homem tardo-moderno, no seu esforço de dar um nome e um rosto à especificidade da própria condição e ao difuso sentido de 'estranheza' ou de 'distância' das ideias-força dos últimos séculos. (FORNERO apud TEIXEIRA, 2005, p. 81).

Na abordagem proposta por Vattimo é conferido à pós-modernidade o status quo daquilo que se designa por um novo paradigma, ou, ainda, uma atitude crítica em relação à lógica da pedra angular do pensamento metafísico-moderno, na tentativa e esperança de elaborar discursos livres, do 'abandono' da Metafísica e de sua lógica (in)superável. Cabe logo anunciar que, conforme o filósofo italiano, o 'pós' de pós-modernidade, sugere "uma despedida da modernidade", que, na medida em que almeja escapar das suas lógicas de desenvolvimento, ou seja, "sobretudo da idéia de 'superação' crítica em direção a uma fundamentação, busca precisamente o que Nietzsche e Heidegger procuraram em sua relação 'crítica' com o pensamento ocidental” (VATTIMO, 1996, p. VII).

Ao lançar mão dos filósofos da Modernidade, como Nietzsche e Heidegger, Vattimo anseia esclarecer que a assim chamada Pós-Modernidade não ambiciona uma "reapropriação" ou uma "nova" fundamentação mais verdadeira, uma vez que empreende toda uma crítica à tradição filosófico-metafísica, a qual não mais abriga a ideia de superação crítica, própria do pensamento moderno, como sendo um constituinte pressuposto da interpretação filosófica. No entanto, procura compreendê-la a partir do precário, no frágil, no oscilante e no fragmentado, valendo-se da atenuação dos arcabouços estáveis do pensamento. Por este percurso, Vattimo não se restringe a um período posterior à Modernidade - sabendo que isso poderia levar a uma representação do ponto de vista moderno-metafísico -: a pós-modernidade aponta, assim, para uma leitura crítica dos ideais legitimadores do período da Modernidade.

Valendo-se da teorização do niilismo ativo e positivo de Nietzsche e da ideia da Verwindung de Heidegger, como caracteres diferentes da ideia de superação críticometafísica no sentido moderno, é possível apreender que a pós-modernidade chegou a um ponto de vista extremado (radical) em relação aos pressupostos modernos. Essa radicalização advém, excepcionalmente, da proposição do enfraquecimento das estruturas do ser, aquelas que percorrem, por exemplo, a leitura ontológico-hermenêutica de Vattimo da condição pósmoderna como oportunidade positiva:

Enquanto o homem e o ser forem pensados, metafisicamente, 
platonicamente, em termos de estruturas estáveis que impõem ao pensamento e à existência a tarefa de 'fundar-se', de estabelecer-se (com a lógica, com a ética) no domínio do não-deveniente, refletindo-se em toda uma mitificação das estruturas fortes em qualquer campo da experiência, não será possível ao pensamento viver positivamente aquela verdadeira idade pós-metafísica que é a pós-modernidade. Não que nela tudo seja aceito como via de promoção do humano; mas a capacidade de escolher e discriminar entre as possibilidades que a condição pós-moderna nos coloca só se constrói com base em uma análise dessa condição que a apreenda em suas características próprias, que a reconheça como campo de possibilidade e não a pense apenas como o inferno da negação do humano. (VATTIMO, 1996, p. XVIII).

A compreensão da pós-modernidade filosófica, deste modo, ganha auxílios da categoria da Verwindung e a sua distinção da Uberwindung (metafísico-dialética) que, por ocasião, possibilita identificar a presença de determinadas circunscrições da herança nietzscheano-heideggeriana nas reflexões vattimianas.

A despeito de a Verwindung principiar algo que se assemelha à Überwindung, superação ou ultrapassamento (VATTIMO, 1996, p. 169) dialético-metafísico, ela se diferencia desta por não possuir nada da Aufhebung dialética, "nem do 'deixar para trás' que caracteriza a relação com um passado que não tem mais nada a dizer-nos. Ora é precisamente a diferença entre Verwindung e Überwindung que nos pode ajudar a definir o 'pós' do pósmoderno em termos filosóficos" (VATTIMO, 1996, p. 169). Neste caminho é percebível que Vattimo reconhece na Verwindung o sinal da filosofia na contemporaneidade na apresentação das implicações encontradas nas definições nietzscheanas da morte de Deus e do mundo do Ge-Stell heideggeriano, tomando para si, deste modo, o aspecto cardeal do surgimento da própria dimensão pós-moderna da filosofia.

Assim, o conteúdo pós-metafísico da filosofia de Vattimo está representado pelo caráter da Verwindung, o que oferece os parâmetros à pós-modernidade filosófica em uma reconfiguração da tarefa da filosofia, justamente na época do fim da filosofia na sua configuração metafísica, pois

quando falamos do fim da Filosofia queremos significar o acabamento da Metafísica. Acabamento não quer dizer, no entanto, plenitude no sentido que a Filosofia deveria ter atingido, com seu fim, a suprema perfeição. Falta-nos não apenas qualquer medida que permitisse estimar a perfeição de uma época da Metafísica em comparação a outra. (HEIDEGGER, 1996, p. 96).

Vattimo acaba por se valer, em sua argumentação sobre a pós-modernidade filosófica, do pensamento heideggeriano apresentado acima para esclarecer o que seria esse fim da 
filosofia como Metafísica - termos conhecimento, a partir das próprias indicações de Heidegger dadas aos tradutores franceses do Vorträge und Aufsätze, no entendimento vattimiano, é que a

Verwindung indica um ultrapassamento que tem em si as características da aceitação e do aprofundamento. Por outro lado, o significado léxico da palavra no vocabulário alemão contém duas outras indicações: a da convalescença (eine Krankheit verwinden: curar, recuperar-se de uma doença) e a de (dis)torção (um significado bastante marginal, ligado a winden, torcer, e ao significado de alteração desviante que, entre outros, o prefixo ver possui. Liga-se ao sentido de convalescença também o de 'resignação': não se verwindet apenas uma doença, mas se verwindet também uma perda, uma dor. (VATTIMO, 1996, p. 179).

Entretanto, embora a categoria da Verwindung não tenha sido usada por Nietzsche, Vattimo (1996) a extrai dele a partir do abandono nietzscheano da lógica de superação moderna, a qual Nietzsche chamou de "doença histórica”. Essa expressão nietzschiano deve ser entendida como algo que indica o excesso de conhecimento do passado, o epigonismo com o qual se atravanca o surgimento (surgimento no sentido de criação) de novas histórias:

O excesso de história me parece nocivo e perigoso para a vida por cinco razões: ele engendra a oposição anteriormente evocada entre interioridade e a exterioridade, enfraquecendo assim a personalidade; ele leva uma época a imaginar que possui a virtude mais rara, a justiça, num grau mais elevado do que qualquer outra época o fez; ele perturba os instintos do povo e impede o amadurecimento tanto do individuo quanto da comunidade; ele implanta a crença sempre nociva na velhice da humanidade, a crença de que ela própria é um epígono tardio; ele leva uma época a adotar a perigosa atitude da ironia a respeito de si mesma e, em seguida, uma atitude ainda mais perigosa, o cinismo: com esta atitude, ela evolui cada vez mais na direção de uma habilidade prática que serve a fins egoístas, através da qual todas as forças vitais ficam paralisadas e finalmente são destruídas. (NIETZSCHE, 2005, p. 107-108).

Nessa perspectiva, pode-se dizer que a Modernidade é tida por Nietzsche como a “época da história" que ficou assinalada pela "doença histórica”. Essa época apresenta como fundamental aspecto a categoria de superação crítica, idealizada, temporal e teoricamente, como um lapso irrefreável de fenômenos, no intuito de chegar a um embasamento mais coerente, suficiente e verossímil do desenvolvimento da humanidade. ${ }^{5}$ Daí o ensejo pelo qual Vattimo (1996) passa a compreender a Verwindung como "convalescença", ou seja, como despedida da Modernidade ou da sociedade moderna. Por isso, pode-se dizer que a pós-

\footnotetext{
5 Podemos afeiçoar este aspecto como o "modismo" da Modernidade.
} 
modernidade é uma época, ou é a época, pós-metafísica, que foi concebida não apenas como época de superação da Metafísica e da Modernidade.

Sem que isso implique ultrapassamento crítico, nem como pura aceitação ou retomada, as errâncias da Metafísica passam a ser, nessa pós-modernidade, apenas levadas em conta como 'temas' a serem rememorados. Entretanto, não são levados excepcionalmente em consideração apenas os significados da Verwindung radicada em Nietzsche e Heidegger, mas, também, o Andenken (rememoração) que Vattimo apropinqua à filosofia da manha $\tilde{a}^{6}$ nietzschiana, a qual chama de pensamento pós-metafísico. Tal feitio de aproximação proporciona o distanciamento da lógica de superação dialética (Aufhebung) no momento em que se emprega a Verwindung à herança metafísica. Nestes termos, Bodei (2000, p. 266) ressalta que Vattimo toma a Verwindung como despedida das ideias fortes da tradição metafísica, como contraposição à Aufhebung dialética.

A reviravolta (Kehre) do pensamento de Heidegger "[...] é, como se sabe, a passagem de um plano em que existe apenas o homem (o existencialismo humanista à Sartre) a um plano em que há principalmente o ser, como diz o escrito de 1946 sobre o humanismo" (VATTIMO, 1996, p. 181). O filósofo italiano credita, portanto, tal aproximação à própria Kehre do pensamento heideggeriano nos anos de 1930, quando se analisa, sobretudo, a direção desconstrutiva, o aniquilamento da história da ontologia, presente na obra de Heidegger, intitulada de Ser e Tempo.

Vattimo (1996) destaca possibilidades de aproximação em torno das reflexões de Nietzsche e de Heidegger, como, por exemplo: a decorrência niilista da autodissolução da noção de verdade e de fundação nietzschiana, a qual se aproxima da epocalidade do ser descoberta por Heidegger; e, principalmente, a tese da renúncia da concepção do ser como Grund (Fundamento). Assim, Andenken e Verwindung expressam o sentido estrito da filosofia como hermenêutica, uma filosofia da interpretação que se encontra extremamente próxima da dimensão ontológica que qualifica o ser como

transmissão das aberturas histórico-destinais que constituem, para cada humanidade histórica, je und je, a sua específica possibilidade de acesso ao mundo. A experiência do ser, enquanto experiência de recepção-resposta dessas transmissões, é sempre Andenken e Verwindung (VATTIMO, 1996, p.

\footnotetext{
${ }^{6} \mathrm{O}$ que Nietzsche chama de uma filosofia da manhã, é "[...] o pensamento não mais orientado com base na origem ou no fundamento, mas na proximidade. Esse pensamento da proximidade também poderia ser definido como um pensamento do erro; ou, melhor ainda, da "errância", para ressaltar que não se trata de pensar o nãoverdadeiro, mas de encarar o devir das construções 'falsas' da metafísica, da moral, da religião, da arte - todo esse tecido de erronias que constituem a riqueza ou, mais simplesmente, o ser da realidade" (VATTIMO, 1996, p. 176).
} 
184).

Portanto, com o uso substantivo de Verwindung, dada toda essa constatação, "acredita o italiano poder assentar melhor as bases filosóficas da pós-modernidade" (SILVA, 2011, p. 157). No que concerne à Metafísica, se ela "chegou ao fim, deve-se dela convalescer e recuperar-se - isto se faz possível, a princípio, pela resignação ou aceitação dessa perda e, em consequência, distorcer o seu sentido, não apresentando algo de novo que venha a substituíla" (SILVA, 2011, p. 157). Assim,

a pós-modernidade, como remédio para o fim da metafísica, ou luto elaborado, no dizer de Lyotard, não poderia designar mais uma etapa do pensamento - sobretudo, como Vattimo já adianta na Introdução ao Fim da Modernidade, seria a constatação de uma perda e, ao mesmo tempo, a recuperação dessa perda, não podendo apresentar-se como uma nova metafísica. Dos dois sentidos do fim da metafísica organizados por Vattimo, quanto à saída da modernidade, pela via da desmistificação da verdade e pelas noções de convalescença e resignação, a pós-modernidade surge como resultado e perspectiva face ao fim da metafísica, na qual o ser e o homem se determinam não mais como a filosofia tradicional teria estabelecido. (SILVA, 2011, p. 157).

No entanto, tem-se ainda o ingresso do homem e do ser, como aponta Vattimo (1996), numa realidade oscilante e aliviada (âmbito da schwingend), numa dilatação entre o "verdadeiro e a ficção, a informação, a imagem", donde germina o "mundo da mediatização total da nossa experiência, no qual já nos encontramos em larga medida" (VATTIMO, 1996, p. 189-190). Isto, portanto, consiste na concepção da pós-modernidade como fim da história, ao passo em que se assemelha com a imobilidade técnica. Segundo o filósofo,

no ponto em que a justificação do pós-moderno toca o problema da comunicação generalizada, aspecto que Vattimo apenas ventila como proposta à compreensão da experiência contemporânea, interessa reportar-se à obra de 1989, A sociedade transparente, e examinar o papel que os mass media ocupam como possibilidade de manifestação e legitimação das diferenças culturais ou, como Lyotard se expressou, dos diferentes mundos de nomes. (SILVA, 2011, p. 157).

Portanto, em O Fim da Modernidade, "o pós-moderno se define pelo fim da História e o fim da metafísica, perda de que se deve reestabelecer, ao contrário de buscar uma novidade que a ultrapasse" (SILVA, 2011, p. 157). Em A Sociedade Transparente, o pós-moderno abordado por Vattimo tem sentido "no fato da sociedade em que vivemos, ser uma sociedade de comunicação generalizada, a sociedade dos mass media" (VATTIMO, 1992, p. 7). 
Nessa perspectiva, a pós-modernidade, além de constituir uma experiência relativa ao fim da Metafísica, também pode ser vista como a experiência dos mass media. Com ela sedimentou-se novas experiências a partir da comunicação globalizada e novas visões de mundo e culturas dos dialetos, bem como o aparecimento das culturas particulares, a partir do avanço informacional, o que irá implicar em uma nova experiência artística.

\section{Os mass media como a experiência pós-moderna}

Nas argumentações de Vattimo sobre o pós-moderno, compreendemos a pósmodernidade como a sociedade da multiplicação dos sentidos, da publicidade e propaganda irrestritas, principalmente, como espaço da experiência mediatizada, um período em que na sociedade dos mass media permite proliferar diversas histórias. A exemplo, Vattimo (1992) se reporta ao conteúdo jornalístico, ao jornal, em que há diversas notícias impressas em um único fascículo, que diz respeito a um efeito emancipatório em relação ao sentido unitário da história, daqueles vinculados à tradição metafísica. É importante resaltar que, em uma quase unanimidade,

\footnotetext{
os historiadores da filosofia estimam que a modernidade se teria iniciado no século XVII, com Descartes, e terminado no final do século XVIII, com Immanuel Kant. Outros, ao invés, a consideram como um processo que ainda não se consumou. É o que pensam, por exemplo, Badiou, Jambet, Lardreau e, numa perspectiva patentemente conservadora, Habermas, para quem a modernidade se desenvolve como um "projeto inacabado", ou em via de perfazer-se. Do outro lado da arena se colocam pensadores dos mais diversos matrizes - Heidegger, Deleuze, Lyotard, Derrida, Foucault, Kofman, Vattimo, Rorty, Nancy, Lacoue-Labarthe - cujo maioria vê em Nietzsche um chefe de fila e aos quais foi indistintamente aplicado o epíteto de "pós-moderno". (ALMEIDA, 2012, p. 251).
}

Sem apreensão, e de maneira geral, estes últimos filósofos citados declaram ser a nossa época marcada pelo "signo da subjetividade" e ela estaria, ademais, andando para a sua realização final. E, conforme Almeida (2012, p. 256), "foi, de fato, a partir do início do século XX que se intensificaram os debates e as análises em torno do conceito de modernidade". Portanto, se em torno do conceito de "modernidade" é impossível encontrar uma definição que seja completa, precisa ou satisfatória de uma vez por todas, "a tarefa não se tornará menos difícil de encontrar um conceito não menos ambíguo de "pós-modernidade" (ALMEIDA, 2012, p.268). 
Em virtude do prefixo "pós", tem-se inicialmente a impressão de que a pósmodernidade não é, senão, uma sequência cronológica da modernidade. Tal impressão não é de todo incorreta, visto que não se pode concebê-la sem o período que a precedera. O que ocorre, porém, é que não se trata de uma continuidade lógica ou de uma evolução necessária e linear que estaria, por assim dizer, inscrita no destino mesmo do vir-a-ser. Conforme Almeida (2012, p. 268), estamos diante de uma "exclusão interna", a saber: "as rupturas e os ataques que se operam contra as ideias modernas da razão, de progresso, de finalidade, de universalidade, de igualdade e emancipação só puderam nascer do mesmo solo, das mesmas raízes", ou, mais precisamente, das próprias forças que lançaram essas ideias, mas que, depois, "perderam a potência ou a capacidade de se imporem as forças" (ALMEIDA, 2012, p. 268). Daí,

não obstante isso - ou por causa disso mesmo - novas e diferentes forças ressurgem acarretando com elas um mundo variegado de metamorfoses e, portanto, de perspectivas, de releituras, de reinterpretação e revalorizações com as quais não se havia jamais sonhado. É nisto, repita-se, que reside a ambiguidade do niilismo: constroem novos valores na medida mesma, no momento mesmo, no átimo mesmo em que os antigos valores se destroem e as antigas forças que os criaram se veem exauridas, esgotadas, superadas, transformadas e, assim, retornadas contra si mesmas. (ALMEIDA, 2012, p. 268-269).

Segundo Vattimo (1996), na Modernidade, a concepção histórica era unidirecional e progressiva; já na Pós-Modernidade, esta mesma concepção agora é estabelecida por múltiplas visões. Nessa última, o papel dos mass media se tornou um fator preponderante à concepção de mundo dessa nova sociedade, estreada àquela altura. Com o fim da Modernidade e a concretização de uma nova experiência, agora oferecida pela pósmodernidade, se instaurou uma problemática pela qual temos como pressuposta a ação dos meios de comunicação ou, nos termos utilizados por Gianni Vattimo (1989), a ação dos mass media. Segundo Reginaldo Silva (2011, p. 149), “com Vattimo, o apelo à legitimação das culturas regionais ganha o auxílio dos mass media, de tal modo que ele pode sustentar que a época pós-moderna engendra uma sociedade de comunicação generalizada, a sociedade dos mass media".

O sentido de emancipação aqui é o aludido pelo próprio Vattimo (1992) como aquela posta pelos meios de comunicação de massa (mass media) e os seus reflexos na experiência artística na sociedade pós-moderna. Conforme o autor, esse sentido e seus reflexos precisam ser entendidos como positivos para o contexto histórico-cultural designado, ou seja, para a 
sociedade contemporânea - assim tomada como circunscrita à pós-modernidade. Tal feição evidencia, na medida em que dá destaque à posição que os mass media ocupam nessa nova reconfiguração de sociedade, o sentido de tal emancipação a partir da "exploração cultural" na atualidade, situando nossa sociedade como sendo, nos termos de Vattimo (1992, p. 7), uma "sociedade da comunicação generalizada".

Na leitura vattimiana, os media são considerados determinantes para efetivação do fim da história no sentido moderno-metafísico-historicista, pressupondo que a modernidade "[...] termina quando - por múltiplas razões - já não parece possível falar de história como qualquer coisa de unitário. De facto, uma tal visão da história implicava a existência de um centro em torno do qual se recolhem e se ordenam os acontecimentos" (VATTIMO, 1992, p. 8). Constatado tal evento, Vattimo (1992) profere que a insurgência de culturas colonizadas coloca o ideal europeu de humanidade como mais um entre outros ideais - rompendo com a ideia do eurocentrismo. Assim, a atuação dos media tem efeito incontestável que marca a experiência atual, a do alargamento do horizonte das culturas particulares. Segundo Vattimo (1992, p.9),

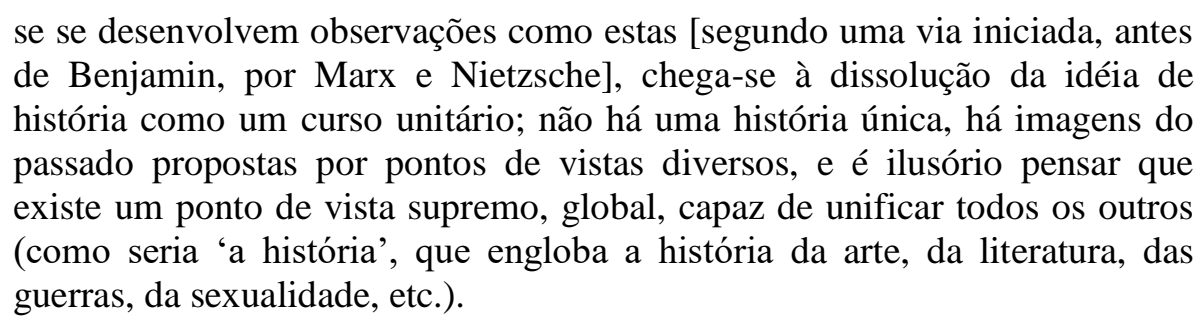

A preocupação é compreender o aspecto situacional das novas condições efetivas, levando em consideração a técnica ${ }^{7}$ e o sistema de informação, vistos por um prisma positivo para a humanidade. É graças à esfera de mediações proposta pelos mass media, que se tornou impensável e inviável a perspectiva de uma história universal, como era exposta no período da Modernidade, prevalecendo, para Vattimo, a irrupção de histórias destituídas de quaisquer aspirações metafísicas.

Adotando o prefixo pós à Modernidade, àquela a qual ele chama de sociedade dos media (comunicação de massa), Vattimo (1992) apresenta sua tese reconhecendo nesse

\footnotetext{
${ }^{7}$ Segundo Almeida (2005, p. 259), "para Heidegger, é a técnica que manifesta a essência do mundo moderno na medida em que o homem ocidental, pelo esquecimento, do Ser, se volta primeiramente para os entes naturais ou para as coisas na sua expressão ôntica. Nestas, ele exerce o seu primado e a sua maestria; pela técnica ele as transforma e as utiliza sistematicamente para a sua própria vantagem, mas, ao fazê-lo, é o ser próprio pensamento que também se torna tecnicizado, objetivando ou determinado por essas realidades suscetíveis de manipulação".
} 
prefixo a expressão de um novo horizonte positivo para o pensamento Ocidental, o que outrora induziu o declínio do pensamento moderno do Ocidente ${ }^{8}$. Nos termos utilizados pelo próprio autor, o "pós-moderno tem um sentido; e que este sentido está ligado ao fato da sociedade em que vivemos ser uma sociedade da comunicação generalizada, a sociedade dos mass media" (VATTIMO, 1992, p. 7). Nesse contexto, o autor reconhece a pós-modernidade como um novo contexto cultural (o ethos da diversidade), que representa, além de outras coisas, a "destruição" das fronteiras culturais, o que agora é possível graças à intervenção das tecnologias informacionais.

O fim da marginalização cultural é decorrência dos referidos mass media, diz Vattimo (1992). Tal feitio se dá por eles, os media, colocarem em pauta os elementos de culturas locais, seus dialetos, as minorias, embora se saiba que, em certo sentido, eles também expandem e fortalecem hegemonias culturais. Os meios de comunicação proporcionaram a dissolução das grandes narrativas ${ }^{9}$, e com a ação dos mass media na sociedade contemporânea,

o que de facto aconteceu, porém, não obstante todos os esforços dos monopólios e das grandes centrais capitalistas, é que a rádio, a televisão, os jornais se tornaram elementos de uma grande explosão e multiplicação de Weltanschauungen, de visões de mundo. (VATTIMO, 1992, p. 11).

Percebe-se que a sociedade da comunicação generalizada possibilitou visibilidade para as minorias e subculturas. Segundo Vattimo (1992), as novas visões de mundo acomodaram o requerimento do fim da marginalização cultural. Contudo, o filósofo reconhece a existência de um desvio nos mass media, mas não perde o seu otimismo quanto à interferência positiva deles na pós-modernidade.

A este desvio, entende-se que,

de fato, uma tal possibilidade parece ao alcance da mão: bastaria que os mass media, que são os modos em que a autoconsciência da sociedade se transmite a todos os seus membros, não se deixassem já condicionar por ideologias, interesses de setores, etc., e se tornassem de alguma forma 'órgão' das ciências sociais, se sujeitassem à medida crítica de um saber

\footnotetext{
${ }^{8}$ Entende-se que o "declínio do Ocidente significa, aqui, a dissolução da idéia de um significado e de uma direção unitária da história da humanidade, espécie de alicerce, na tradição moderna, do pensamento ocidental. Este considerava a sua própria civilização como o nível máximo evolutivo alcançado pela humanidade em geral e, baseado nisso, sentia-se chamado a civilizar, mesmo a colonizar, converter, submeter todos os povos com os quais entrava em contato." (VATTIMO, 1999, p. 43).

9 Diferente de Vattimo, Adorno criticava os mass media por acreditar que eles estavam em função da lógica econômica e produziam a homologação da sociedade capitalista (Cf. VATTIMO, 1992).
} 
rigoroso, difundissem uma imagem 'científica' da sociedade, precisamente aquela que as ciências humanas estão já em condições de construir. (VATTIMO, 1992, p. 28).

É a partir da atuação dos media que se dá a emancipação das culturas particulares, que consiste "mais no desenraizamento, que é também, e ao mesmo tempo, libertação das diferenças, dos elementos locais, daquilo que poderíamos chamar, globalmente, o dialecto" (VATTIMO, 1992, p. 14). Temos, deste modo, com a atuação dos media na pós-modernidade, uma multiplicidade de culturas particulares inseridas no âmbito da comunicação generalizada, cada qual se expressando em suas condições próprias. Assim "o sentido emancipador da libertação das diferenças e dos 'dialectos' consiste mais no efeito global de desenraizamento que acompanha o primeiro efeito de identificação" (VATTIMO, 1992, p. 15).

\section{A experiência artística a partir dos media}

A partir da emancipação da cultura dos dialetos e das diferenças que configuram o espaço da pós-modernidade, situamos a experiência artística como mais uma consequência da ação dos media, visto observar algumas modificações categóricas na mesma. Segundo Vattimo (1992), esse novo contexto em que a arte ingressa evidencia que a própria obra de arte e a experiência artística deparam-se com um horizonte cultural bastante diferente do que, outrora, a tradição artística propusera.

Em tais termos, a "experiência artística" dessa sociedade, como aponta Vattimo, sofre transformações em sua constituição e em seu sentido, as quais já estão anunciadas no ensaio "A obra de arte na era da reprodutibilidade técnica", de Walter Benjamin, publicado pela primeira vez em 1936. Deste modo, com o intuito de marcar os efeitos da atuação dos media presentes na "experiência artística", Vattimo (1989) se apropria da reflexão benjaminiana, o que acomoda o caráter da experiência cultural na pós-modernidade, justificando a necessidade de empreender uma reflexão mais acurada sobre esta mesma discussão.

Após as cogitações de Benjamin em torno da arte, Vattimo (1992) acredita que as reflexões posteriores às dele, sobre a experiência artística, além de serem insustentáveis, não entenderam a nova essência da obra de arte produzida na pós-modernidade pela técnica, nos termos vattimianos, pela ação dos mass media. Assim, ele faz constantes referências a Benjamin em sua discussão, e tal feito é elucidado por Benjamin ter tecido reflexões desde a compreensão da história numa perspectiva das culturas inferiores até a problemática da obra 
de arte na época de sua reprodutibilidade técnica ${ }^{10}$.

Na pós-modernidade, a insustentabilidade das reflexões a respeito da arte, no contexto das tecnologias, advém do fato de não ser possível enxergá-la para além da tradição artística. No entanto, Vattimo (1992) assinala a obra de arte inserida na sociedade dos media como algo positivo. Reportando-se a Benjamin, repropõe uma reflexão sobre as suas postulações, indicando uma defesa de que precisamos considerar a técnica (os mass media) como condições positivas à produção artística na pós-modernidade. Nos dizeres de Vattimo,

estas várias leituras do ensaio de Benjamin parecem, porém, largamente insuficientes. Aquilo em que é preciso voltar a refletir é a intuição central de tal ensaio, isto é, a ideia de que as novas condições da produção e da fruição artística que surgem na sociedade dos mass media modificaram de maneira substancial a essência, o Wesen da arte (um termo que aqui usaremos no sentido de Heidegger: não a natureza eterna da arte, mas o modo de dar-se na época atual). (VATTIMO, 1992, p. 52).

Portanto, segundo Vattimo, os defensores da aura artística, que também são leitores benjaminianos, almejam meramente o afastamento da obra de arte da vida cotidiana, com o intuito de que se possa adotar um caráter crítico em relação à existência. Entretanto, a essência da arte na pós-modernidade encontra-se com a ação dos media, presente cotidianamente, cada vez com maior intensidade (Cf. VATTIMO, 1992). Tal constatação justifica o motivo que levara o filósofo italiano a propor uma reflexão sobre os novos aspectos da arte, a partir da ação dos mass media e das postulações benjaminianas.

Prontamente, o aspecto da reprodutibilidade é peculiar à arte na contemporaneidade, mas é mais característico o impacto dela no cotidiano, impacto que se encontra presente no cinema. Segundo Benjamin (1994, p. 172), o cinema é considerado a constatação mais dinâmica da reprodução da arte, transformando-a num fenômeno de massa (ou, diríamos, segundo Vattimo, dos mass media). Segundo Vattimo (1992), o que aconteceu, mediante os media na pós-modernidade, foi a transposição da obra de arte para o lugar da vida cotidiana, tornando-a, deste modo, objeto de consumo e nivelando-a às condições socioculturais proporcionadas pela sociedade atual. Na percepção de Benjamin, essa transposição é positiva e determinante à arte, que acaba por ter recebido um valor expositivo adaptável às exigências dos mecanismos de reprodução.

Deste modo, a acepção estética da arte ganha um espaço maior, como também a

\footnotetext{
${ }^{10}$ Titilo atribuído por Benjamin a um de seus ensaios. Nesse ensaio o autor anuncia que a obra de arte perdeu sua aura a partir das técnicas de reprodução, popularizando-se e em oposição à tradição artística.
} 
interpretabilidade no nível cultural e, em alguns aspectos, da sociedade pós-moderna, como é o caso do cinema. O espectador é compelido a viver e conviver em meio aos constantes processos de adaptação e readapção, devido à série de imagens projetadas pelo cinema (VATTIMO, 1992). A presença do cinema na vida cotidiana permitiu a desmistificação da arte e a levou ao horizonte cotidiano que nunca obteve antes. Nesse aspecto, a arte passa a pisar em um solo marcado pela oscilação e, por sua vez, não eternizado, como almejava a tradição.

Esse contexto em que está inserida a obra de arte ofereceu uma experiência de desenraizamento que é entendida e defendida por Vattimo (1992), ao interpretar os escritos de Benjamin (1994). Desenraizamento, segundo Vattimo, consiste na experiência constante de libertação. A libertação aqui está relacionada à derrubada da "ideia de uma realidade central da história", a sociedade da comunicação generalizada onde se explode uma multiplicidade de racionalidades locais ${ }^{11}$, que assumem a palavra, "finalmente já não silenciadas e reprimidas pela ideia de que só existia uma única forma de verdadeira humanidade a realizar, com prejuízo de todas as peculiaridades, de todas as caracterizações limitadas, efêmeras, contingentes" (VATTIMO, 1992, p. 15). Este processo de libertação das diferenças,

\begin{abstract}
diga-se de passagem, não é necessariamente o abandono de todas as regras, a manifestação informe da demarcação: também os dialectos têm uma gramática e uma sintaxe, mas só quando conquistam dignidade e visibilidade descobrem a sua própria gramática. A libertação das diversidades é um acto com que elas "tomam a palavra", se apresentam, se "põem em forma" de modo a poderem tornar-se reconhecidas; de modo algum uma manifestação bruta de imediato. (VATTIMO, 1992, p. 15).
\end{abstract}

Tal feito destina à estética um universo de possibilidades desse desenraizamento, uma vez que se segue o compasso dos novos meios de produção e reprodução artística. A teoria estética da tradição metafísica não admitiu as possibilidades que os media oferecem à experiência artística $^{12}$ porque acreditam que os mass media perseguem a essencialidade da arte apenas em termos de criatividade e conciliação.

A causa que motivou a teoria estética da tradição metafísica a não reconhecer a

\footnotetext{
${ }^{11}$ Segundo Vattimo (1992, p. 15), "o efeito emancipador da libertação das racionalidades locais não é todavia apenas o de garantir a cada uma delas um mais completo reconhecimento e 'autenticidade'; como se a emancipação consistisse em manifestar finalmente aquilo que cada um é 'verdadeiramente' (ainda em termos metafísicos, espinosianos): negro, mulher, homossexual, protestante, etc. O sentido emancipador da libertação das diferenças e dos 'dialectos' consiste mais no efeito global de desenraizamento que acompanha o primeiro efeito de identificação".

12 A teoria estética da tradição metafísica enxerga os mass media como ameaças e procura rejeitá-los (VATTIMO, 1992).
} 
possibilidade de produção/reprodução proposta pelos media, foi o fato de eles banalizarem qualquer espécie de mensagem e a própria teoria estética apresentar-se como uma reação ao consumo posto pelos mass media (VATTIMO, 1992). Em relação ao não reconhecimento das condições colocadas pelos mass media por parte da teoria estética, Vattimo dirá que:

com efeito, a todos os conteúdos que divulgam, os mass media conferem um peculiar caráter de precariedade e superficialidade; este choca duramente contra os preconceitos de uma estética sempre inspirada, mais ou menos explicitamente, no ideal da obra de arte como "monumentum aere perennius", e da experiência estética como experiência que envolve profunda e autenticamente o sujeito, criador ou expectador. Estabilidade e perenidade da obra, profundidade e autenticidade da experiência produtiva fruidora são certamente coisas que já não podemos esperar na experiência estética da modernidade avançada, dominada pela potência (e impotência) dos media. (VATTIMO, 1992, p. 63).

A partir dessa perspectiva, pode-se dizer que na experiência estética e na arte, atualmente, encontram-se o precário e o superficial, por conseguinte, distanciando-se dos elementos da eternidade e profundidade, como a requeridas pela tradição. Esse novo caráter da arte e da experiência pós-moderna deve ser reconhecido graças ao papel desempenhado pelos media: o de transformação e transposição da essencialidade da experiência artística. Conforme Vattimo (1992), isso pode ser visto no deslocamento do eixo artístico que, pela intervenção dos media, não está mais centrada na própria obra, mas na experiência. Portanto, a experiência artística apresenta o seu sentido de desenraizamento a partir dessa mudança, que é compreendida com a ação dos media. Sendo assim, esta experiência representa um rompimento com a perspectiva artística tradicional, que defendia a experiência artística em termos de autenticidade e a arte em termos de eternidade (VATTIMO, 1992).

Em relação às objeções feitas sobre a ação dos mass media na experiência artística pós-moderna, por sua vez, atuante na sociedade da comunicação generalizada, Vattimo (1992) diz serem elas equivocadas pelo fato de situar esse novo contexto como nível predominantemente da alienação política, não enxergando as boas novas trazidas pelos media. O fato de a teoria estética da tradição metafísica não fazer essa distinção aponta para uma maneira como os seus seguidores equivocam-se e não compreendem que a superficialidade e a precariedade existentes na experiência estética não são, necessariamente, estruturas de alienação. Por este caminho, Vattimo profere:

Contrariamente ao que durante muito tempo - e com boas razões, 
infelizmente - acreditou a sociologia crítica, a massificação niveladora, a manipulação do consenso, os erros do totalitarismo não são o único resultado possível do advento da comunicação generalizada, dos mass media, da reprodutibilidade. Ao lado da possibilidade - que deve ser decidida politicamente - destes resultados, abre-se também uma possibilidade alternativa: o advento dos media comporta também efectivamente uma acentuada mobilidade e superficialidade da experiência, que contrasta com as tendências para a generalização do domínio, ao mesmo tempo em que dá lugar a uma espécie de "enfraquecimento" da própria noção de realidade, com o conseqüiente enfraquecimento também de toda a sua coacção. A "sociedade do espetáculo" de que falaram os situacionistas não é apenas a sociedade das aparências manipuladas pelo poder; é também a sociedade em que a realidade se apresenta com características mais brandas e fluidas, e em que a experiência pode adquirir os aspectos da oscilação, do desenraizamento, do jogo. (VATTIMO, 1992, p. 65).

Deste modo, o exposto até este momento sugere para uma efervescência cultural na pós-modernidade a partir da ação dos mass media, nos quais se situam aspectos da experiência artística, apontados por Vattimo, e da própria arte. Incluso nessa tematização, o autor reporta-se a sua obra $O$ Fim da Modernidade, onde ele discute sobre o fim do pensamento metafísico, pensamento este tratado nas reflexões dos filósofos Nietzsche e Heidegger e avocados, por ele mesmo, para falar sobre a morte ou ocaso da arte ${ }^{13}$.

Nesse contexto, a problemática instaurada a partir do evento contemporâneo em nossa experiência histórico-cultural é de que a arte não é mais entendida como algo específico ou isolado da experiência. Sua perspectiva, como algo privilegiado, como o era na tradição filosófica, entrou em declínio e se tornou débil na pós-modernidade a partir da atuação dos mass media.Vattimo (1996) aponta esse ocorrido em termos de ocaso, uma vez que a arte se realiza em sentido tradicional. Contudo, esse sentido não possui mais tanto impacto na experiência artística pós-moderna como na tradição, visto que a arte, nessa nova atmosfera, problematiza-se e vai além dos seus próprios limites.

Vattimo sustenta que é a partir dos mass media, das tecnologias da comunicação e informação, que a experiência estética na atualidade passa a assumir aquele caráter de desenraizamento ao promover a multiplicação de belos na condição artística na contemporaneidade. O que se observa é uma

\footnotetext{
${ }^{13}$ A morte da arte é um conceito de Hegel e Vattimo o relaciona à crise dos fundamentos. Segundo Vattimo, o que morre não é a arte, mas o conceito de arte da tradição. Vattimo contrapõe a morte ao ocaso, argumentando que a arte passou do conteúdo eterno, divino, para o finito, o que permitiu sua libertação, fazendo-a ter inúmeros e infinitos sentidos. Assim, a arte passa a ser tão somente profana a partir da atuação dos media, aceitando cada vez mais a contingência e a particularidade, perde sua áurea poética originariamente mítica para dar lugar à prosa desacralizada, a cultura dos dialetos, aceitando o feio, o dissonante, o estranho, o finito (Cf. VATTIMO, 1992).
} 
experiência através do uso das técnicas da reprodução mecânica da arte. Morte da arte não é apenas a que podemos esperar da reintegração revolucionária da existência: é aquela que de fato já vivemos na sociedade da cultura de massa, em que se pode falar da estetização geral da vida na medida em que a mídia, que distribui informação, cultura, entretenimento, mas sempre sob critérios de 'beleza' (atração formal dos produtos), assumiu na vida de todos um peso infinitamente maior que em qualquer outra época do passado. (VATTIMO, 1996, p. 44).

Tal feito permite dizer, a partir da concepção vattimiana, que um dos efeitos concretos da atuação dos mass media na pós-modernidade está no fato de que, na medida em que distribuem informações, eles estabelecem, ao nível da esfera pública, atuando sobre o consenso e sobre o compartilhamento de sentimentos semelhantes.

A experiência artística inserida nesse contexto, na contemporaneidade densamente marcada pelos media, é tida como uma estetização geral. De fato o que acontece é que os media promovem, a partir da divulgação de informações, da própria cultura, e da Moda, como aponta Vattimo (1996), uma estetização que carrega consigo o signo de beleza e, por conseguinte, a diversidade de vários belos, evidenciando, assim, que tal estetização é mais um feitio de descentralização e que, simultaneamente, reconhece a diversidade cultural.

Segundo Vattimo (1996, p. 44-45),

\begin{abstract}
Identificar a esfera da mídia com o estético pode, por certo, levantar algumas objeções, mas não é tão difícil admitir semelhante identificação, se se levar em conta que, além de e mais profundamente do que distribuir informação, a mídia produz consenso, instauração e intensificação de uma linguagem comum no social. Ela não é um meio para a massa, a serviço da massa; é um meio da massa, no sentido de que a constitui como tal, como esfera pública do consenso, dos gostos e dos sentimentos comuns. Ora, essa função, que se costuma chamar, com um acento negativo, de organização do consenso, é uma função por excelência estética, pelo menos num dos sentidos principais que esse termo assume desde a Crítica do juízo kantiana, na qual o prazer estético não se define como aquele que o sujeito experimenta pelo objeto, mas como aquele prazer que deriva da constatação de pertencer a um grupo - em Kant, a própria humanidade como ideal -, unido pela capacidade de apreciar o belo.
\end{abstract}

Esta decorrência, assim sendo, faz jus de ser interpretada como positiva para uma sociedade pós-moderna, como o próprio Vattimo diz, por ela ser realizada, uma vez que os mass media tornam acessíveis e realizáveis experiências estéticas na contemporaneidade, fora dos costumeiros espaços artísticos, realizando-se em diferentes lugares, nos quais intuímos que a estetização geral de belos desponta da expansão do domínio e da ampliação cultural percebidas a partir do ideal emancipatório de culturas particulares, como alvitre dos media. 


\section{Considerações finais}

A partir das indicações críticas feitas pelos filósofos Nietzsche e Heidegger na Modernidade, especialmente no que se refere à categoria da Verwindung em oposição à Überwindung, Vattimo apresenta a pós-modernidade como uma radicalização da tradição filosófica moderna. A filosofia pós-moderna, conforme anunciada por Vattimo, leva alguns aspectos em consideração, como as implicações resultantes do niilismo, da modernidade, da crise da Metafísica e da acepção global da história, da presença e intervenção dos mass media, do desenraizamento e, notadamente, da perda de força das estruturas estáveis, implicando na compreensão enfraquecida do ser. Pode-se dizer que a orientação da pós-modernidade filosófica proposta por ele é expressa a partir da categoria da Verwindung, o que consente em uma reconfiguração do próprio papel da filosofia na época em que a Metafísica chega ao fim.

O niilismo é refletido nessa conjectura como sendo uma característica necessária para a compreensão da existência na pós-modernidade, experiência que é profundamente influenciada pela herança nietzscheano-heideggeriano, que Vattimo recebe e a qual dá continuidade. Em tais termos, Vattimo encontra ressonância e dá anuência a seu discurso sobre o pós-moderno, no campo da filosofia, a partir do anúncio de Nietzsche da "morte de Deus", implicando em uma grande importância para o pensamento filosófico na contemporaneidade.

A pós-modernidade vattimiana é concebida como a experiência do "fim da história", do rompimento com a metafísica que a tradição filosófica na modernidade usou para a leitura dos fatos históricos, como também da crise dos discursos totalitários e globalizantes que outrora configuravam o paradigma do historicismo. Assim, a pós-modernidade como "fim da história" implicaria a dissolução do "sentido global" atribuído à história nos múltiplos sentidos, eventos, informações e práticas discursivas sociais.

Nessa esteira, reconhecer a pós-modernidade como sendo a época do "fim da história" implica em dizer que a experiência de tal fim é, também, consequência da presença e experiência dos mass media. Daí, Vattimo designar a sociedade pós-moderna como "sociedade da comunicação generalizada", na qual os pontos de vistas centrais são diluídos em benefício das culturas locais, das subculturas marginalizadas. Para além dos aspectos que destoam dos mass media, Vattimo se atém à dimensão de emancipação que eles, os mass media, possibilitam às racionalidades locais, à experiência da estetização, aos dialetos e 
minorias marginalizados antigamente pela condução metafísico-eurocêntrica.

Apesar de sua visão otimista, Vattimo reconhece as barreiras existentes na sociedade capitalista, atribuídas ao papel dos mass media. Porém, “quando levamos em consideração os efeitos sociais e políticos do primeiro grande meio de comunicação de massa, isto é, a invenção da imprensa por Gutemberg, podemos verificar sua importância para democratização da cultura" (CHAUI, 2006, p. 26). Por isso, observa-se ainda que o pensamento vattimiano é acompanhado pela dimensão estética.

Podemos constatar tal feitio em sua reflexão sobre o fim da Metafísica, dando ênfase à pergunta do sentido de tal fim para a Estética e para a arte. Nessa perspectiva, podemos dizer que a Estética é uma das principais vertentes do pensamento do filósofo, não se limitando apenas a um elemento dessa filosofia.

Tendo em vista o caminho que Vattimo faz em sua reflexão filosófica em A Sociedade Transparente e em O Fim da Modernidade, compreende-se que ele segue no horizonte da experiência estética, conduzindo a sua crítica ao ideal metafísico proposto pela modernidade. Nessa esteira, a especulação vattimiana defende que a obra de arte e a experiência estética na contemporaneidade estão em um horizonte cultural que difere bastante da tradição artística. Ou seja, na pós-modernidade, com os media, os acontecimentos artísticos se realizam para além das instituições clássicas da arte.

Pode-se dizer que a originalidade da reflexão vattimiana reside no fato de ela conceber que, com o advento dos media - da sociedade da comunicação, dos meios de comunicação -, se perde a centralidade das coisas, o molde linear que antigamente foi conferido à história na Modernidade, pois que a partir dos mass media, na pós-modernidade, a obra de arte tornou-se objeto de consumo comum.

Entende-se esse lugar comum no sentido de que os medias "transportam" a obra de arte para outros lugares, para o mundo, com maior facilidade e celeridade, com informações intensificadas, constituindo, portanto, uma multiplicidade de belos, ao mesmo tempo em que conferem novos modos de estetização. Tal constatação evidencia que os media rompem com a tradição estética, com a ideia de estética unificada a partir do eurocentrismo, e corroboram com o aparecimento da diversidade de subsistemas artísticos ao constituírem uma "generalização da esteticidade".

Deste modo, na sociedade pós-moderna, a experiência estética adquire um sentido tecnológico que está em oposição ao ideal outrora encontrado na Modernidade. Em outros termos, a atuação dos mass media na contemporaneidade provoca o desenraizamento das 
condições utópicas do moderno e proporciona o aparecimento do heterotopismo pós-moderno, a emancipação do pensamento, (re)configurando o pensamento filosófico ocidental. Hoje, encontramos na sociedade uma efervescência cultural, e Vattimo precisou-o com seu olhar filosófico.

Portanto, o cotidiano, tendo em vista a reflexão de Vattimo, possui hoje um novo sentido graças à comunicação generalizada. Com os media, a própria experiência artística afastou-se da sua inteligibilidade passando a fazer parte da vida cotidiana. Essa conjectura diz respeito à emancipação cultural presente na sociedade contemporânea enquanto experiência pós-moderna e mostra-se como uma possibilidade para a sociedade vista às condições de vida na contemporaneidade.

\section{Referências}

ADORNO, Theodor W.. Dialética do esclarecimento: fragmentos filosóficos. Tradução Guido Antônio de Almeida. Rio de Janeiro: Jorge Zahar Editora, 1985.

ALMEIDA, Rogério M.. A fragmentação da cultura e o fim do sujeito. São Paulo: Edições Loyola, 2012.

ANDERSON, Perry. As origens da pós-modernidade. Tradução Marcus Penchel. Rio de Janeiro: Zahar Editores, 1999.

BENJAMIN, Walter. Magia e técnica, arte e política: ensaios sobre literatura e história da cultura. Tradução Sérgio Paulo Rouanet. 7. ed. São Paulo: Brasiliense, 1994.

BODEI, Remo. A Filosofia do século XX. Tradução Modesto Florenzano. São Paulo: EDUSC, 2000.

CHAUI, Marilena. Simulacro e poder: uma análise da mídia. São Paulo: Editora Fundação Perseu Abramo, 2006.

HEIDEGGER, Martin. O Fim da Filosofia e a Tarefa do Pensamento. Conferências e Escritos Filosóficos. São Paulo: Nova Cultural, 1996.

LYOTARD, Jean-François. A condição pós-moderna. Tradução por Ricardo Corrêa Barbosa. José Olympio, 2008.

NIETZSCHE, Friedrich. II Consideração Intempestiva sobre a utilidade e os inconvenientes da Historia para a vida. In: Escritos sobre História. São Paulo: Loyola, 2005.

SILVA, Reginaldo O.. O Pós-moderno explicado às diferenças: a sociedade dos mass media em Gianni Vattimo. Argumentos - Revista de Filosofia. Ano 3, №. 6, p. 149-160, 2011. 
TEIXEIRA, Evilázio B.. Aventura Pós-moderna e sua sombra. São Paulo: Paulus, 2005.

VATTIMO, Gianni. O fim da modernidade: hermenêutica e niilismo na cultura pósmoderna. Tradução Eduardo Brandão. São Paulo: Martins Fontes, 1996.

VATTIMO, Gianni. Sociedade transparente. Tradução Hossein Shooja e Isabel Santos. Lisboa: Relógio D’Água Editores, 1992.

VATTIMO, Gianni; ROVATTI, A.P. Il Pensiero Debole. Milano: Feltrinelli Editore, 1983.

VATTIMO, Gianni. As Aventuras da Diferença: o que significa pensar depois de Heidegger e Nietzsche [1980]. Lisboa: Edições 70, 1988.

VATTIMO, Gianni. A filosofia e o declínio do Ocidente. Revista FAMECOS, [S.1.], v. 1, n. 10, abr. 2008. ISSN 1980-3729. Disponível em: <http://revistaseletronicas.pucrs.br/ojs/index. php/revistafamecos/article/view/3027>. Acesso em: 05 Mar. 2016. 